Supplement of Atmos. Chem. Phys., 17, 77-92, 2017

http://www.atmos-chem-phys.net/17/77/2017/

doi:10.5194/acp-17-77-2017-supplement

(C) Author(s) 2017. CC Attribution 3.0 License.

(c) (i)

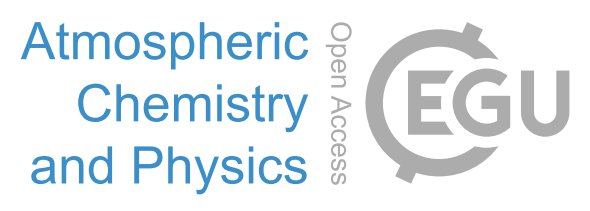

Supplement of

\title{
Modeling biogenic and anthropogenic secondary organic aerosol in China
}

Jianlin Hu et al.

Correspondence to: Qi Ying (qying@ civil.tamu.edu)

The copyright of individual parts of the supplement might differ from the CC-BY 3.0 licence. 
Table S1 Predicted seasonal average precursor contributions (\%) to glyoxal SOA. GLY_A1 and GLY_A2: glyoxal SOA from oxidation of aromatics with $\mathrm{OH}$ reaction rate $<2 \times 10^{4} \mathrm{ppm}^{-1} \mathrm{~min}^{-1}$ and $>2 \times 10^{4} \mathrm{ppm}^{-1} \mathrm{~min}^{-1}$, respectively; GLY_I: glyoxal from oxidation of isoprene; GLY_O: glyoxal from direct emissions and oxidation of other precursors

\begin{tabular}{lllll} 
& GLY_A1 & GLY_A2 & GLY_I & GLY_O \\
\hline Spring & 17.4 & 7.2 & 24.4 & 50.9 \\
Summer & 7.3 & 5.0 & 52.5 & 35.2 \\
Autumn & 16.0 & 9.0 & 25.0 & 49.9 \\
Winter & 18.9 & 12.5 & 7.7 & 60.9 \\
\hline
\end{tabular}


Table S2 Predicted seasonal average precursor contributions (\%) to methylglyoxal SOA. MGLY_A1 and MGLY_A2: glyoxal SOA from oxidation of aromatics with $\mathrm{OH}$ reaction rate < $2 \times 10^{4} \mathrm{ppm}^{-1} \mathrm{~min}^{-1}$ and $>2 \times 10^{4} \mathrm{ppm}^{-1} \mathrm{~min}^{-1}$, respectively; MGLY_I: glyoxal from oxidation of isoprene; MGLY_T: glyoxal from oxidation of monoterpene; MGLY_O: glyoxal from direct emissions and oxidation of other precursors

\begin{tabular}{llllll}
\hline & MGLY_A1 & MGLY_A2 & MGLY_T & MGLY_I & MGLY_O \\
\hline Spring & 14.7 & 12.1 & 0.3 & 56.7 & 16.2 \\
Summer & 4.6 & 5.9 & 0.3 & 84.7 & 4.5 \\
Autumn & 14.2 & 15.4 & 0.3 & 56.6 & 13.5 \\
Winter & 22.7 & 28.9 & 0.2 & 22.5 & 25.7 \\
\hline
\end{tabular}



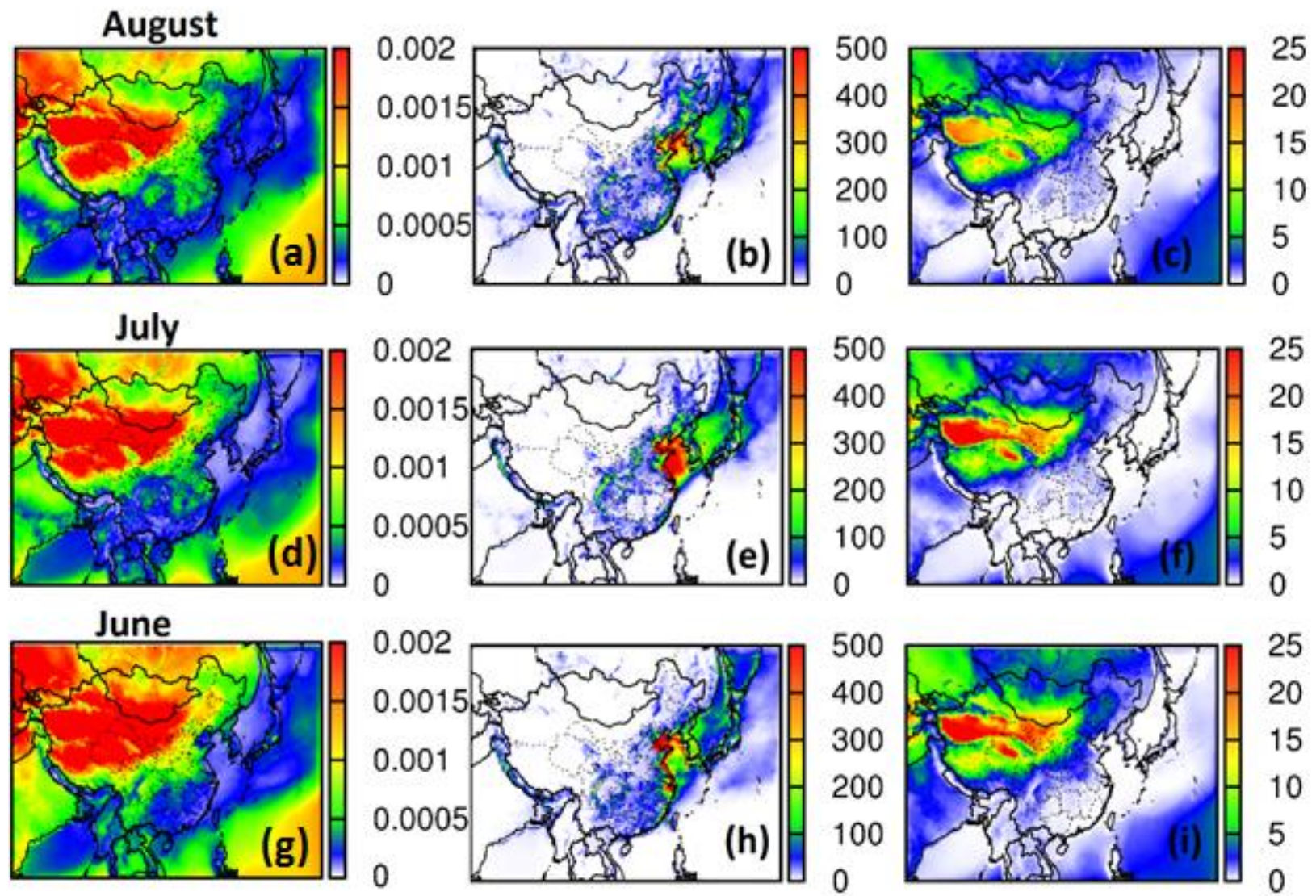

Figure S1 Summertime (a,d,g) uptake coefficients for isoprene epoxides; (b,e,h) aerosol water content $\left(\mu \mathrm{g} \mathrm{m}^{-3}\right)$ and $(\mathrm{c}, \mathrm{f}, \mathrm{i})$ molality of $\mathrm{H}^{+}\left(\mathrm{mol} \mathrm{kg}^{-1}\right.$ water $)$. 

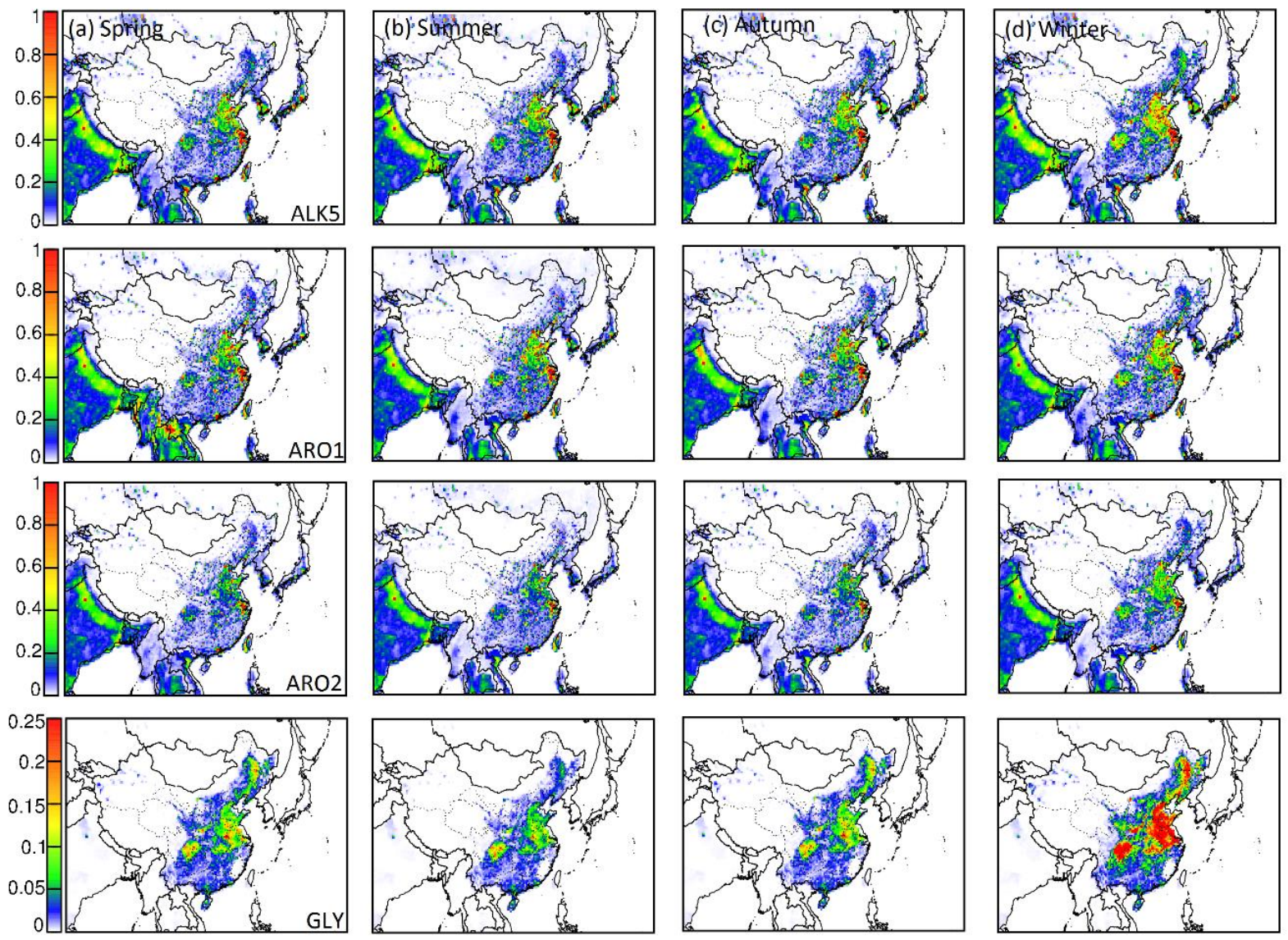

Figure S2 Seasonal average of SOA precursor emission (ALK5, ARO1, ARO2 and GLY) in (a) spring, (b) summer, (c) autumn, and (d) winter 2013. Units are moles s ${ }^{-1}$. 

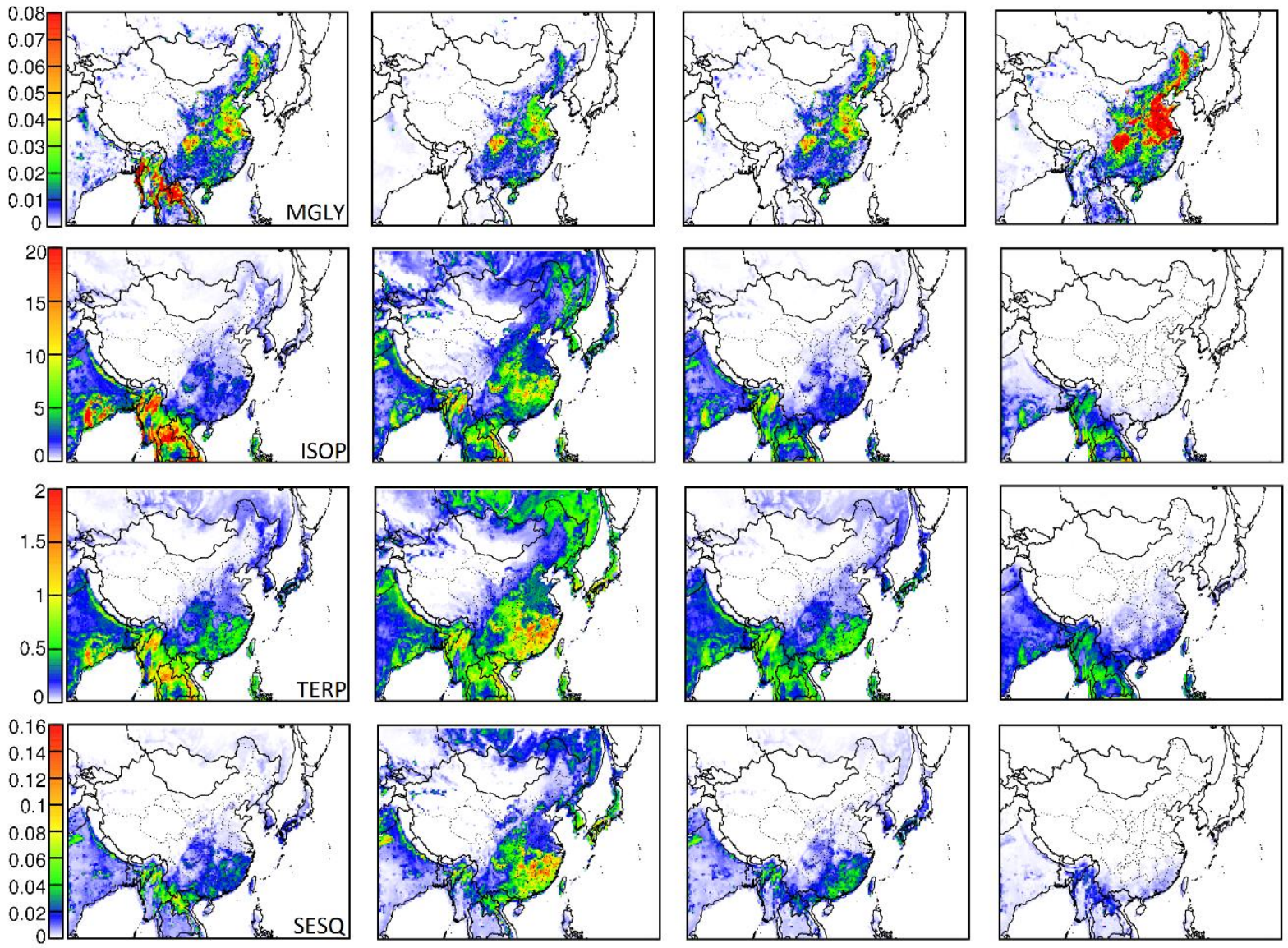

Figure S2 (continue) Seasonal average of SOA precursor emission (MGLY, ISOP, TERP and SESQ) in (a) spring, (b) summer, (c) autumn, and (d) winter 2013. Units are moles s ${ }^{-1}$. 

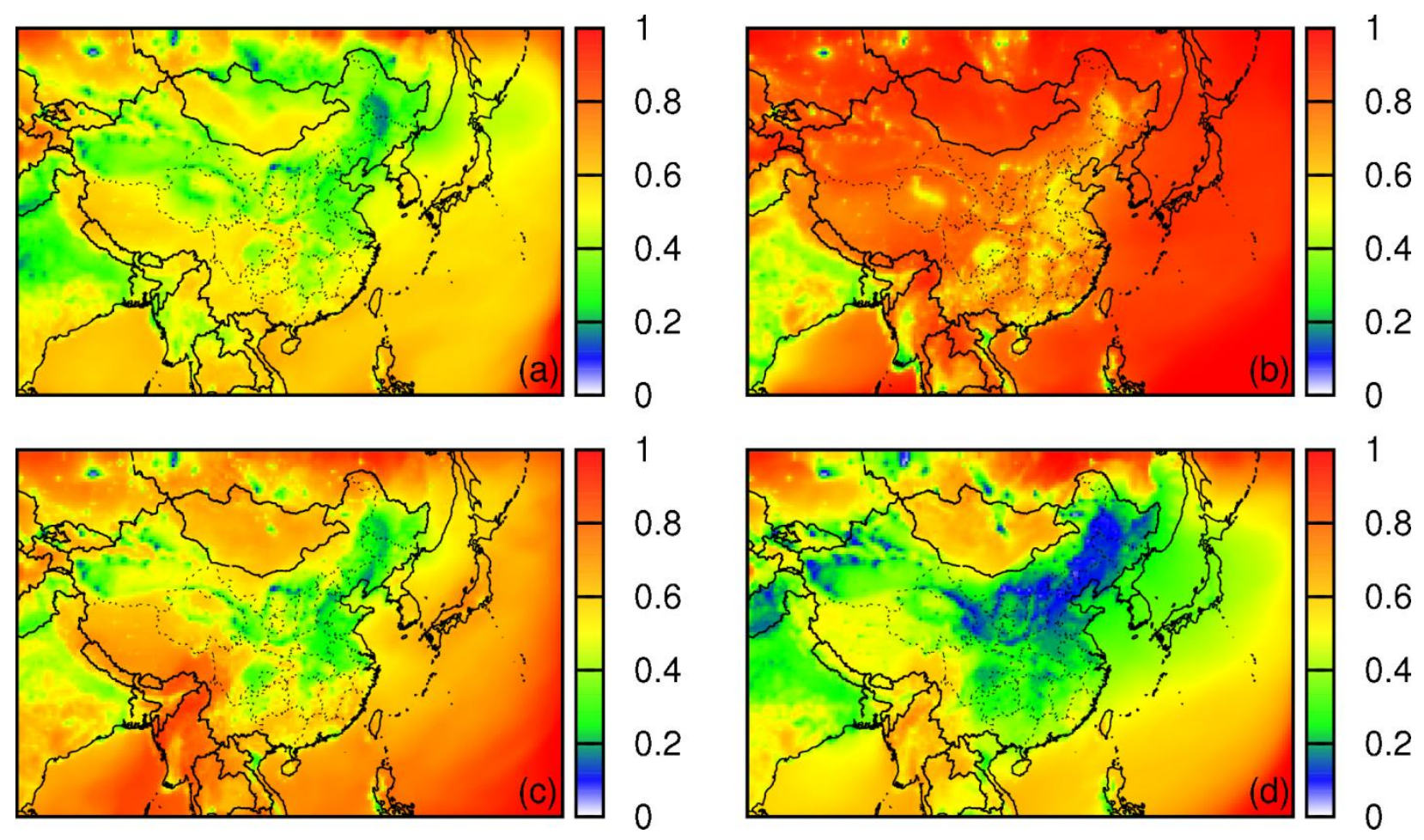

Figure S3 Fractional contributions of predicted SOA to total OA (SOA+POA) for (a) spring, (b) summer, (c) autumn, and (d) winter 2013 

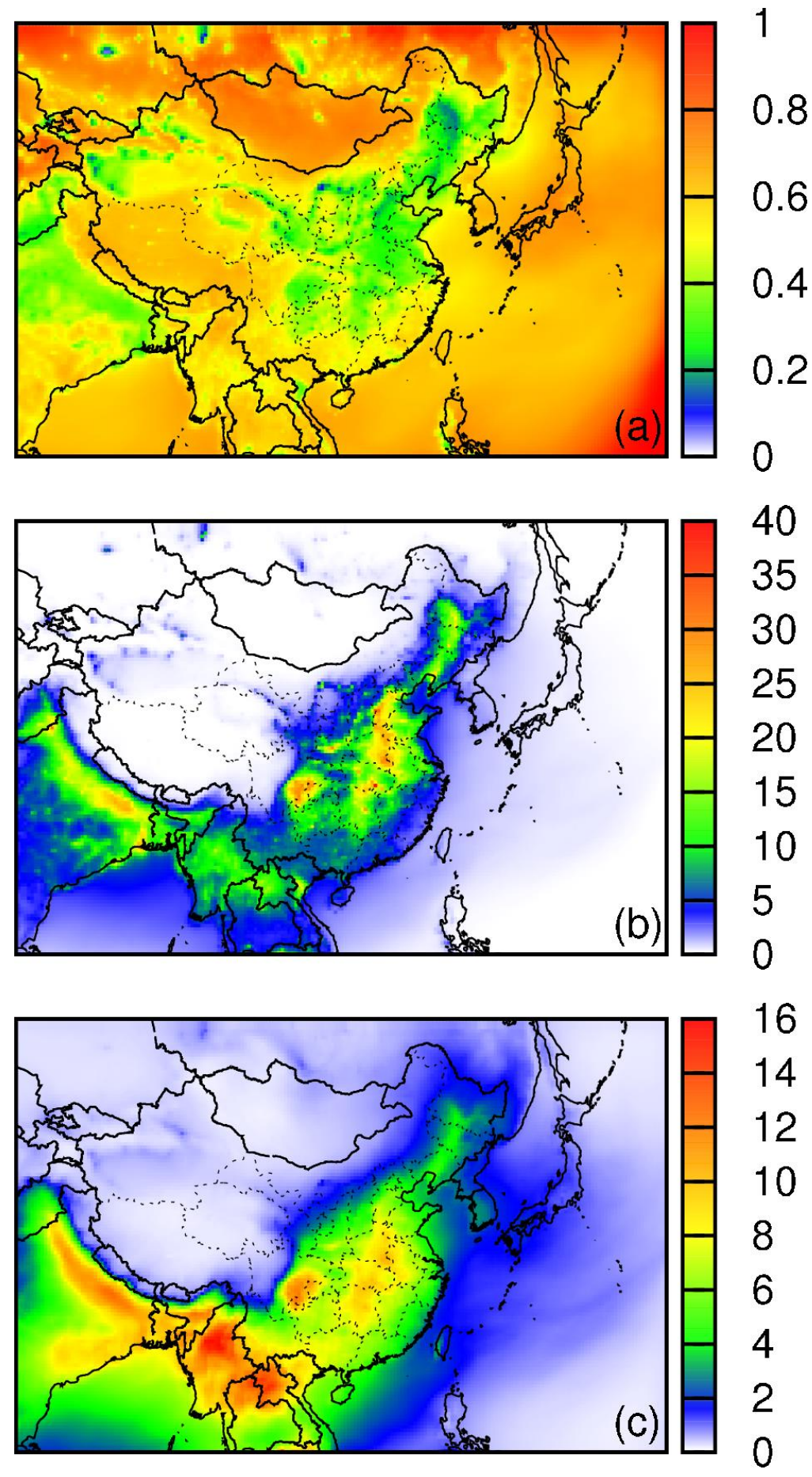

Figure S4 (a) Fractional contributions of predicted annual average SOA to total OA (SOA+POA), (b) annual average POA and (c) annual average SOA. Units are $\mu \mathrm{g} \mathrm{m}^{-3}$. 

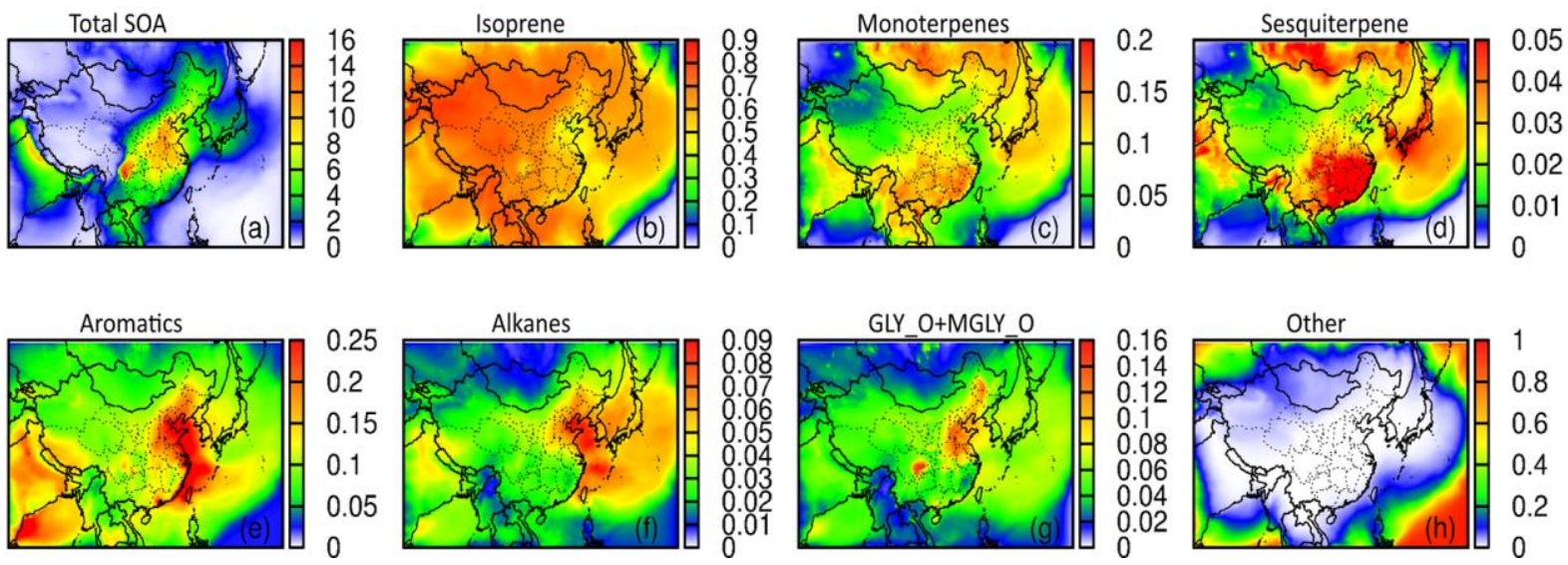

Figure S5 Predicted average SOA concentrations in summer 2013 and relative contributions of different precursors to total SOA. 

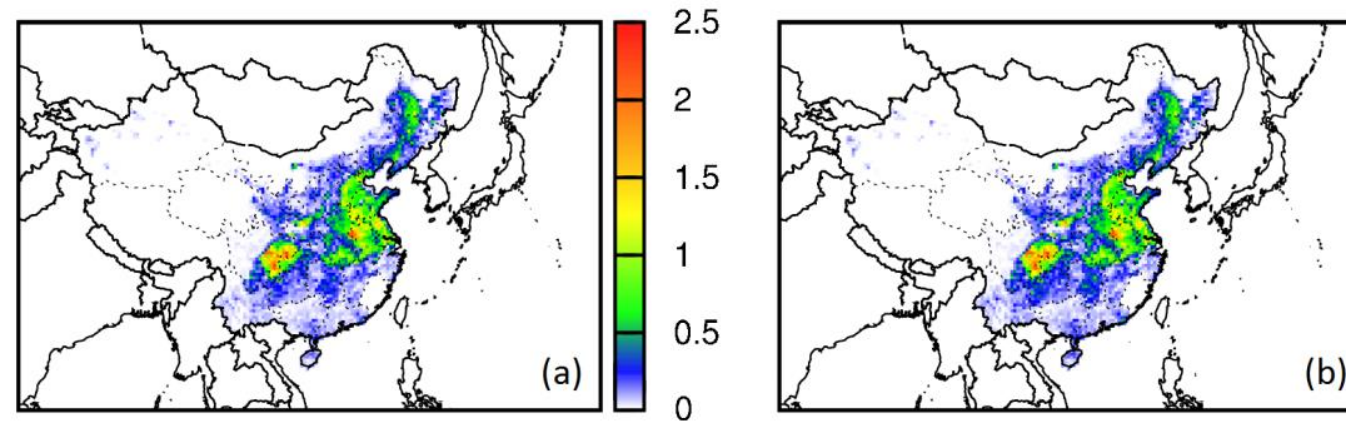

0.9
0.8
0.7
0.6
0.5
0.4
0.3
0.2
0.1
0
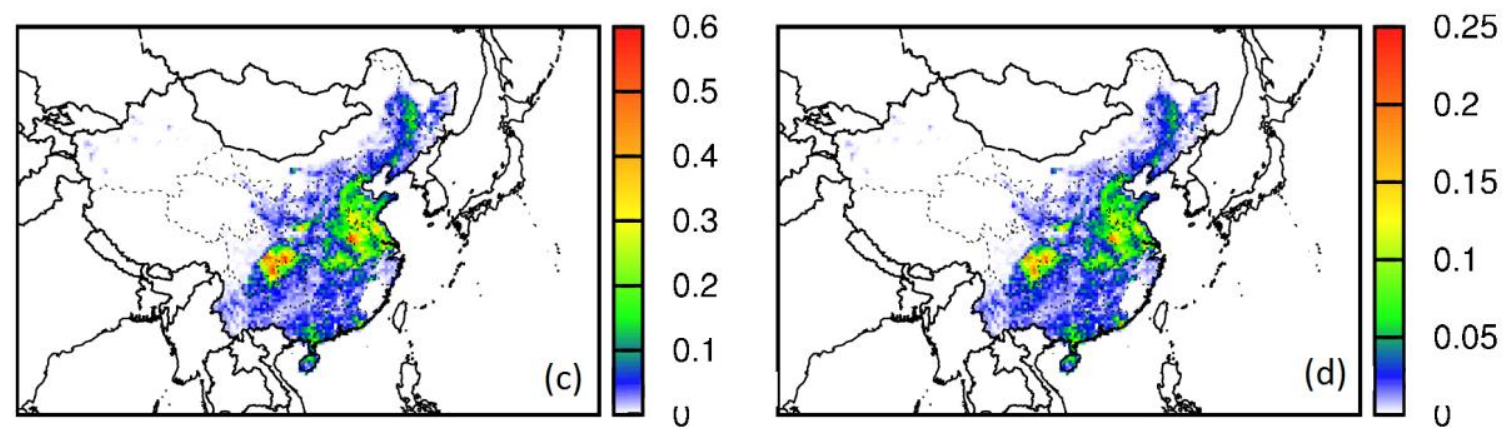

Figure S6 Monthly average emissions of GLY $(a, c)$ and MGLY $(b, d)$ in January and August, 2013. 

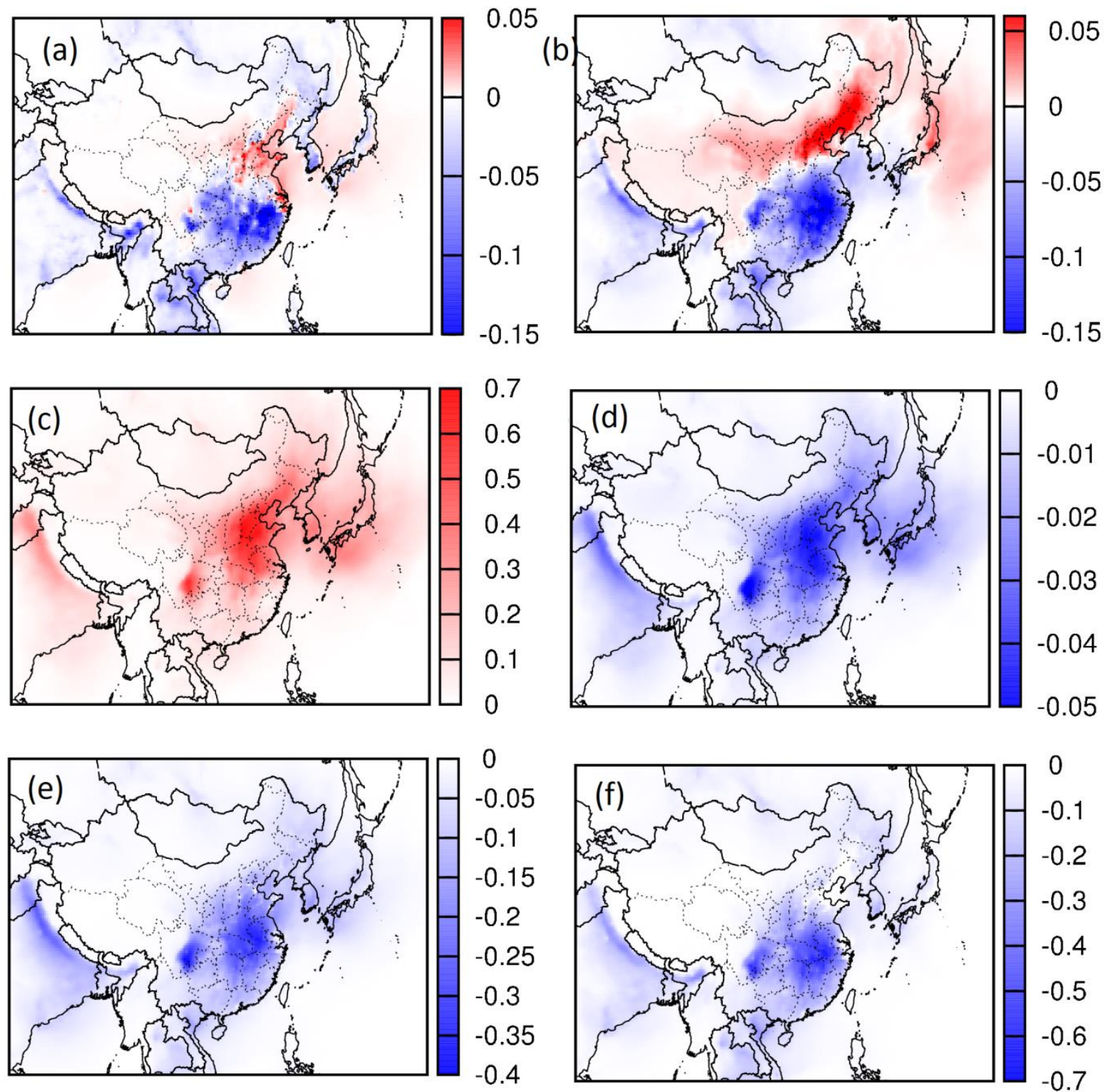

Figure S7 Predicted changes in the spaital distribution of August SOA components (a) semivolatile, (b) oligomers, (c) IEPOX, (d) MAE, (e) GLY and (f) MGLY due to reduction of NOx emission by $50 \%$. (sensitivity case - base case, units are $\mu \mathrm{g} \mathrm{m}^{-3}$ ). 

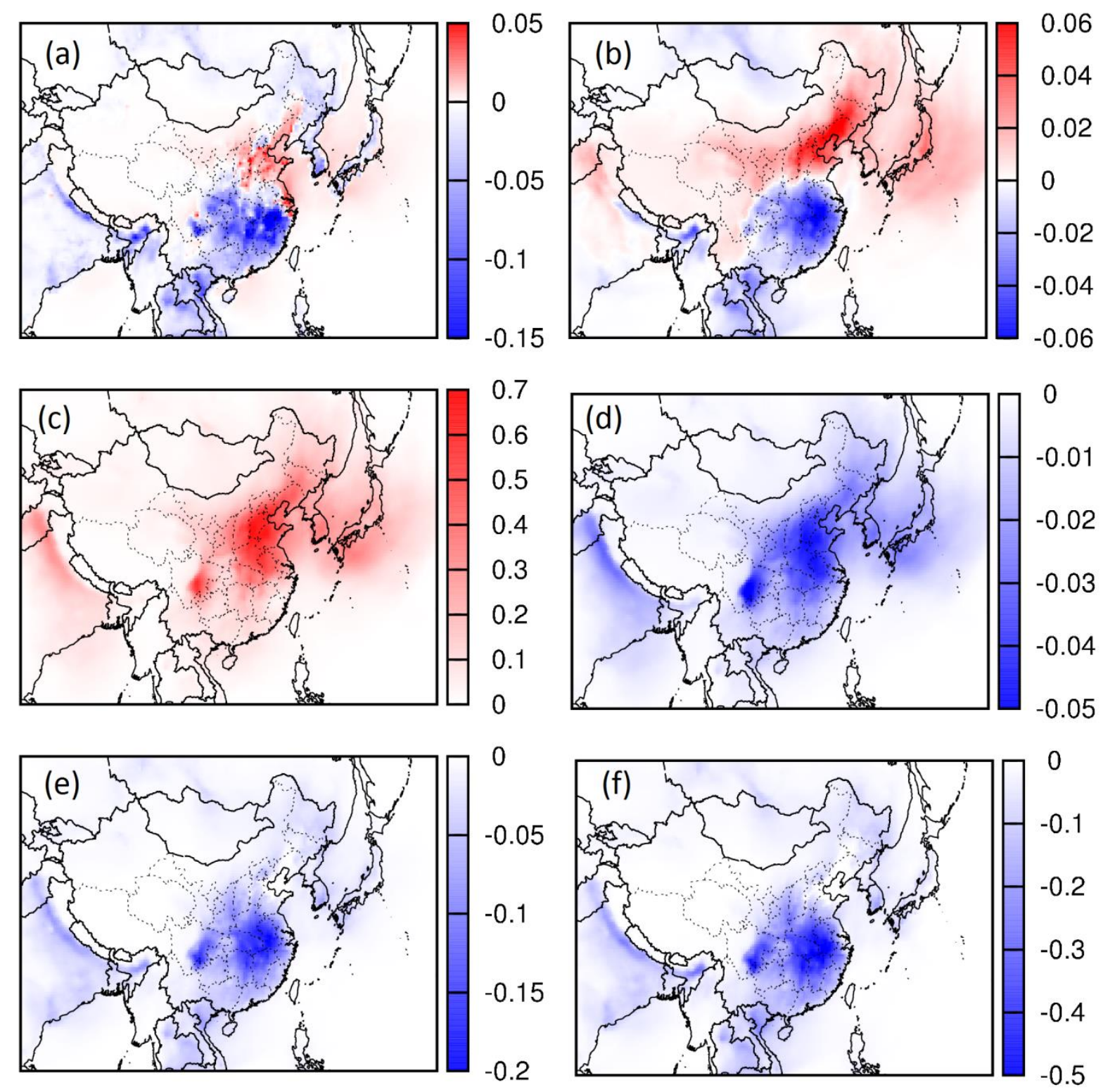

Figure S8 Predicted changes spaital distribution of August isoprene SOA components (a) semivolatile, (b) oligomers, (c) IEPOX, (d) MAE, (e) GLY and (f) MGLY due to reduction of NOx emission by $50 \%$. (sensitivity case - base case, units are $\mu \mathrm{g} \mathrm{m}^{-3}$ ). 

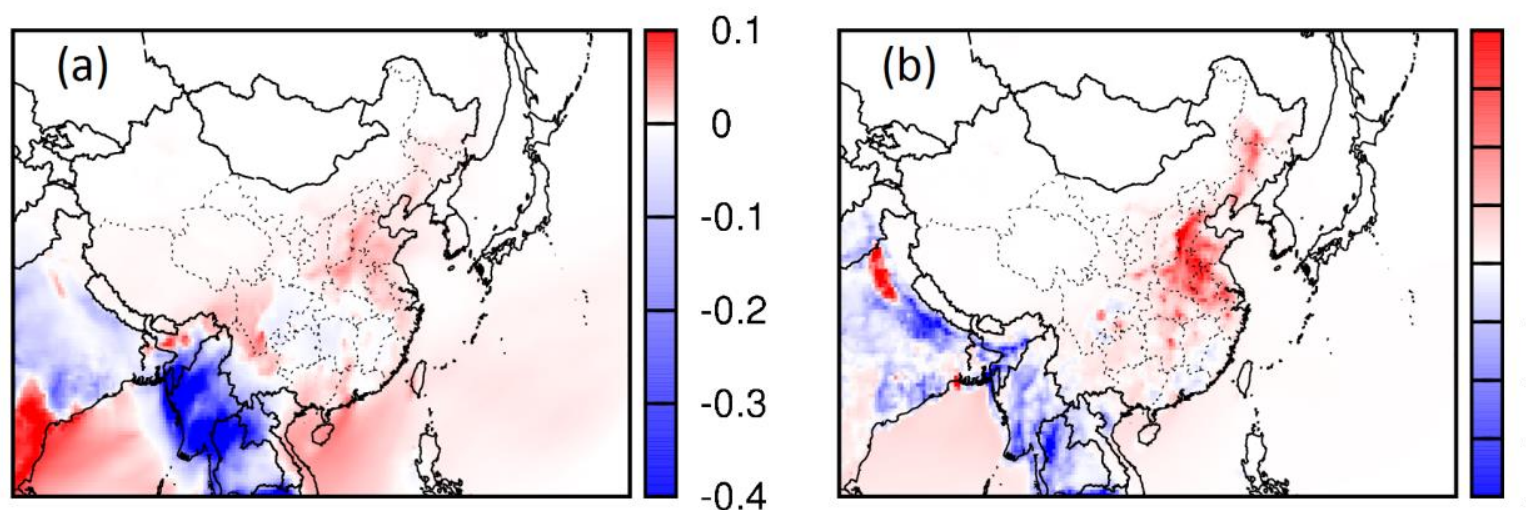

0.2

0.15

0.1

0.05

0

$-0.05$

$-0.1$

$-0.15$
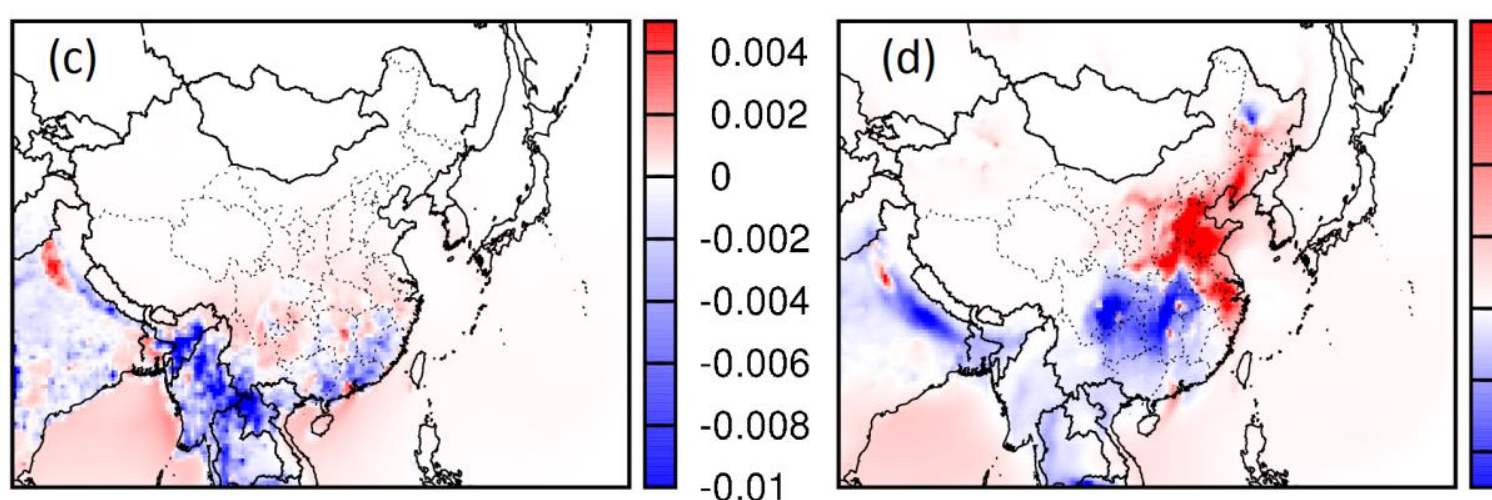

$-0.2$

0.8

0.6

0.4

0.2

0

$-0.2$

$-0.4$
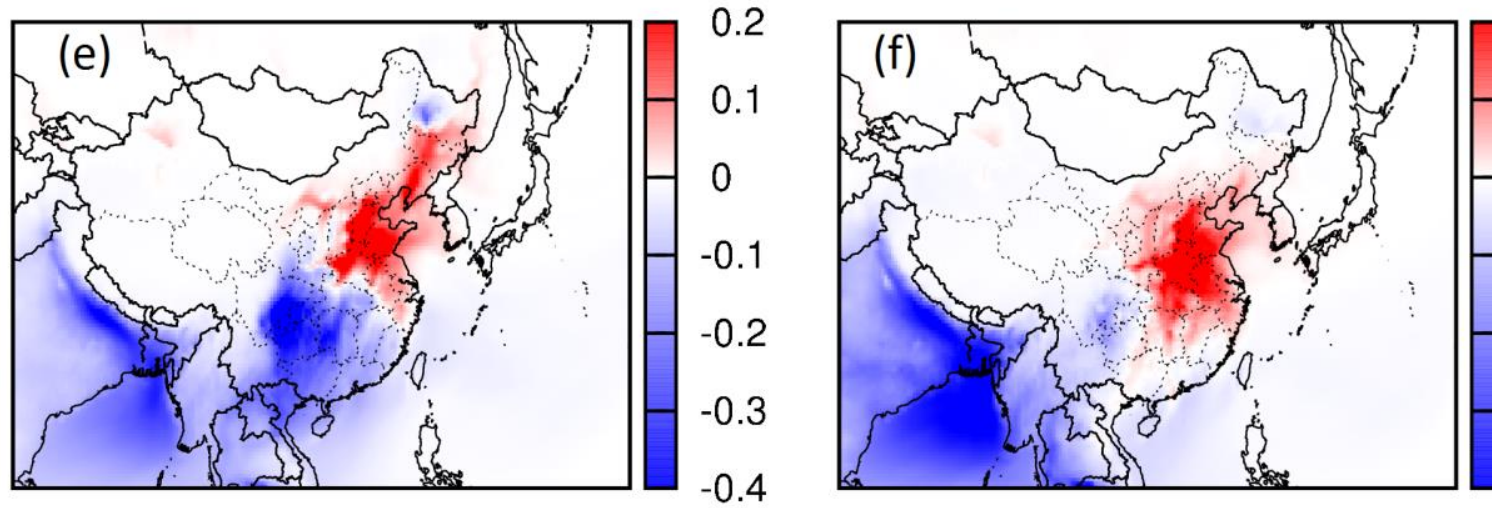

0.1

0.05

0

$-0.05$

$-0.1$

$-0.15$

$-0.2$

Figure S9 Predicted changes in spatial distribution of January SOA from different precursors, (a) ISOP, (b) TERP, (c) SESQ, (d) ARO1+ARO2, (e) ALK5, and (f) primary GLY+MGLY 